has shown that the supposed differences between these two "families" are less clear cut than was supposed.

Although Harris has probably done more than any other worker to piece togother the various organs of bennettitaleans which are normally found detached, his taxonomic treatment of the genera is characteristically empirical. $\mathrm{He}$ avoids the implications of connexion even when this has been very adequately established. $\mathrm{He}$ suggests that "the best treatment at present is to continue to be cautious, to keep the different organs apart under different names, and where one feels sure that certain organs belong to a single plant, to say so, but without affecting the name". To some neobotanists, who might visualize one goal of palaeobotany as the reassembling of whole plants from the fossil pieces (with a concomitant reduction in the number of names), this may sound like a counsel of despair; but to most palaeobotanists it is a philosophy of realism. If applied to all palaeobotanical nomenclature, it would save us from some of the sterile convulsions of name changing to which this science is especially prone.

W. G. Chaloner

\section{PSYCHOTIC STATES}

\section{Psychopathology of the Psychoses}

By Thomas Freeman. Pp. 215. (Tavistock: London, 1969.) $45 s$.

Dr Freeman is a clinical psychiatrist who has been preoccupied with the phenomena of psychotic illness for several years. His method and his point of view will be familiar to readers of his two previous volumes, Chronic Schizophrenia (1958) and Studies on Psychosis (1965). In this book he brings together his clinical experience and his interest in theory to formulate a point of view: "Only the study of psychopathology, with its emphasis on the way in which patients experienco their thoughts, feelings, bodily sensations, and the world around them, can provide the material that will give a reliable foundation for clinical, physiological and biochemical investigations. The major contribution to this psychopathology comes from psychoanalysis".

After a proliminary discussion of the relevant theories advanced by Freud and Hughlings Jackson, the author outlines his method of categorizing and recording the clinical manifestations of psychotic states. Most of the remaining chapters are taken up with a discussion of his scheme in relation to various forms of psychosis, along with illustrative material. A final chapter is conecrned with some of the therapeutic implications of this approach.

The underlying outlook and concepts will not bo new to readers who are familiar with the literature on the subject. Nor will the unconvinced be persuaded that the author has in any way refuted Karl Jaspers's critique of psychoanalysis as a psychology of meaningful, but not explanatory, connexions. None the less, the book is clearly written and gives ample evidence of the care and patience required for the detailed clinical observations on which it is based. More space, however, might have been devoted profitably to the section entitled "Methodology of Clinical Observation" (pages 39-42) in which too little consideration is given to the reliability of the techniques used.

Michael Shepherd

\section{RETURN OF THE OSTRACIZED}

\section{Mental Imagery}

By Alan Richardson. Pp. xii + 180. (Routledge and Kegan Paul: London, August 1969.) 35s.

As Dr Alan Richardson points out in his foreword, the 1950 s and 1960s have seen a re-emergence of interest in mental imagery. He finds one good reason for its study in Robert Holt's 1964 paper "Imagery: the Return of the Ostracized", which shows how imagery can intrude on such activities as radar watching, long distance driving, polar exploration in snow cats and flying jet planes. Modern technological advances compel us to take account of potentially dangerous emergences of imagery and hallucination-like processes, and to return to scientific study of them.

There are also good theoretical reasons for taking account of imagery in an adequately scientific psychology of remembering, perceiving and thinking. Richardson deals with four principal classes: after-imagery, eidetic imagery, memory imagery and imagination imagery. He considers in some detail the curious imagery which some people experience in the hypnagogic or half-asleep state. Richardson's survey deals with early researches like those of Klüver into the stable, vivid and externally projected imagery called by Jaensch "eidetic". More rccent work cited includes Gordon's measurement of controllability of imagery, the factor-analytic studies of Barrett on imagory and of Singer and Antrobus on day-dreaming. Richardson describes his own experiments on mental practice, showing how performance in physical activities like high jumping can be improved by rehearsal in imagery. Stroboscopic experiments in augmenting imagery, EEG studies and the relationship of imagery to mnemonic systems are discussed. The treatment of imagery accompaniments of synaesthesia is largely confined to the work of the Russian Luria, in the detailed study over several decades of one individual subject to this.

The book is stronger in its reporting of the phenomena under study than in its survey of existing theory, or its own contributions to theory. Imagery is discussed largely in terms of two aspects: vividness (as measured by the Bett's scale) and susceptibility to manipulation (as measured by the Gordon test). Many things are mentioned but left undeveloped. Thus the book touchesomewhat lightly on such topics as dream imagery, inters sensory phenomena like synaesthesia, and behaviour therapy in its relation to the uses of imagery. In the treatment of hallucinogens, the incorrect spelling of mescaline (as "mescalin") is unfortunately perpetuated. It is pleasant to be able to welcome a book by a leading Australian psychologist which seeks "to bring together in one place a representative series of facts and hypotheses", after the undeserved neglect of these important and intrinsically interesting phenomena.

Peter McKellar

\section{Obituaries}

\section{Dr B. V. Rollin}

Bernard Vincent Rollin, who died on June 18, was one of a small band of physicists who started research in Oxford in the 1930s under Franz (later Professor Sir Francis) Simon. His first research problem was to design a combined hydrogen and helium liquefier, using the adiabatic expansion method for liquefying helium, which became the basis of the standard "Simple Simon" liquefier used in the Clarendon Laboratory at Oxford. With the help of this liquefier Rollin set out to measure the specific heat of liquid helium as a function of pressure; he discovered in the course of this work that the rate of evaporation from a vessel containing liquid helium increased 